\title{
The importance of chorismate mutase in the biocontrol potential of Trichoderma parareesei
}

\author{
Esclaudys Pérez ${ }^{1}$, M. Belén Rubio ${ }^{1}$, Rosa E. Cardoza ${ }^{2}$, Santiago Gutiérrez ${ }^{2}$, \\ Wagner Bettiol ${ }^{1,3}$, Enrique Monte ${ }^{1 *}$ and Rosa Hermosa ${ }^{1}$
}

1 Department of Microbiology and Genetics, Spanish-Portuguese Centre for Agricultural Research (CIALE), University of Salamanca, Salamanca, Spain, ${ }^{2}$ Area of Microbiology, University School of Agricultural Engineers, University of León, Campus de Ponferrada, Ponferrada, Spain, ${ }^{3}$ Embrapa Environment, Jaguariúna, Brazil

OPEN ACCESS

Edited by:

Jesús Mercado-Blanco,

Consejo Superior de Investigaciones

Cientificas, Spain

Reviewed by:

Christine M. Vos,

University of Leuven, Belgium \& CSIRO Agriculture Brisbane, Australia,

Belgium

Sabrina Sarrocco,

University of Pisa, Italy

*Correspondence:

Enrique Monte emv@usal.es

Specialty section

This article was submitted to Plant Biotic Interactions,

a section of the journal

Frontiers in Microbiology

Received: 29 July 2015 Accepted: 12 October 2015 Published: 27 October 2015

Citation:

Pérez E, Rubio MB, Cardoza RE, Gutiérrez S, Bettiol W, Monte E and Hermosa $R$ (2015) The importance of chorismate mutase in the biocontrol potential of Trichoderma parareesei. Front. Microbiol. 6:1181.

doi: 10.3389/fmicb.2015.01181
Species of Trichoderma exert direct biocontrol activity against soil-borne plant pathogens due to their ability to compete for nutrients and to inhibit or kill their targets through the production of antibiotics and/or hydrolytic enzymes. In addition to these abilities, Trichoderma spp. have beneficial effects for plants, including the stimulation of defenses and the promotion of growth. Here we study the role in biocontrol of the T. parareesei Tparo7 gene, encoding a chorismate mutase (CM), a shikimate pathway branch point leading to the production of aromatic amino acids, which are not only essential components of protein synthesis but also the precursors of a wide range of secondary metabolites. We isolated T. parareesei transformants with the Tparo7 gene silenced. Compared with the wild-type, decreased levels of Tparo7 expression in the silenced transformants were accompanied by reduced $\mathrm{CM}$ activity, lower growth rates on different culture media, and reduced mycoparasitic behavior against the phytopathogenic fungi Rhizoctonia solani, Fusarium oxysporum and Botrytis cinerea in dual cultures. By contrast, higher amounts of the aromatic metabolites tyrosol, 2-phenylethanol and salicylic acid were detected in supernatants from the silenced transformants, which were able to inhibit the growth of $F$. oxysporum and B. cinerea. In in vitro plant assays, Tparo7-silenced transformants also showed a reduced capacity to colonize tomato roots. The effect of Tparo7-silencing on tomato plant responses was examined in greenhouse assays. The growth of plants colonized by the silenced transformants was reduced and the plants exhibited an increased susceptibility to $B$. cinerea in comparison with the responses observed for control plants. In addition, the plants turned yellowish and were defective in jasmonic acid- and ethylene-regulated signaling pathways which was seen by expression analysis of lipoxygenase 1 (LOX1), ethylene-insensitive protein 2 (EIN2) and pathogenesis-related protein 1 (PR-1) genes.

Keywords: shikimate pathway, Tparo7 gene, silencing, antifungal, tyrosol, 2-phenylethanol, salicylic acid 


\section{INTRODUCTION}

The use of biopesticides is an alternative for sustaining high production with low ecological impact in different agricultural production systems (Harman et al., 2010), Trichoderma-based products being the biofungicides available on the market most widely used (Harman et al., 2004; Lorito et al., 2010). Species of Trichoderma protect plants against pathogens owing to the plasticity of their genomes regarding the expression of their abilities to compete for nutrients, the inhibition or killing of plant pathogens through the production of antibiotics and/or cell wall (CW)-degrading enzymes (Druzhinina et al., 2011), the promotion of plant growth, and the induction of defenses against biotic and abiotic damage (Hermosa et al., 2012; Brotman et al., 2013).

Trichoderma parareesei is an efficient cellulase-producing species isolated from soil that has recently been described as a new species (Druzhinina et al., 2010). This species resembles the ancestor that originally gave rise to $T$. reesei and it exhibits the properties of an environmental opportunist (Atanasova et al., 2010). T. parareesei shows fast growth and produces abundant numbers of propagules on a variety of carbon sources, and is adapted to various lighting conditions. In contrast to T. reesei, strains of $T$. parareese $i$ have shown biocontrol potential against fungal and oomycete plant pathogens (Atanasova et al., 2010; Rubio et al., 2014), as well as beneficial effects for plants, in terms of seedling lateral root development, and in adult plants improved defense against Botrytis cinerea and growth promotion under salt stress (Rubio et al., 2014).

The sequencing of Trichoderma genomes has revealed numerous secondary metabolite (SM) gene clusters (Mukherjee et al., 2013). The production of pyrones, peptaibols, terpenes, and polyketides is relevant in this genus (Degenkolb et al., 2006; Reino et al., 2008). Several Trichoderma SMs belonging to these structural families not only exhibit antagonistic activity against plant pathogens (Schirmböck et al., 1994; Rubio et al., 2009), but also have proven beneficial effects in plants (Viterbo et al., 2007; Vinale et al., 2008; Malmierca et al., 2015).

The shikimate pathway (Figure 1) is not present in animals but it is essential in other organisms such as bacteria, fungi, or plants for the synthesis of aromatic compounds, including aromatic amino acids (AAA) tyrosine (Tyr), phenylalanine (Phe), and tryptophan (Trp) (Helmstaedt et al., 2001). Thus, it is a promising target for antimicrobial or antifungal agents and herbicides (Sasso et al., 2004). The shikimate biosynthetic route is connected to central carbon metabolism since it begins with phosphoenolpyruvate (PEP) and erythrose 4-phosphate (E-4P) (Tzin and Galili, 2010). This first step is catalyzed by the enzyme 3-deoxy-D-arabino-heptulosonate-7-phosphate (DAHP) synthase (DAHPS), which is considered to be a critical regulatory checkpoint (Bentley, 1990; Light and Anderson, 2013). The shikimate pathway includes the production of chorismate, the precursor of Tyr and Phe, through the chorismate mutase (CM) enzyme (Romero et al., 1995; Sträter et al., 1997), which also generate a wide range of SMs (Vogt, 2010). CMs can be monofunctional, where they convert chorismate to prephenate through a Claissen rearrangement, or bifunctional, where they subsequently display prephenate dehydrogenase, prephenate dehydrate, or DAHPS activities (Tohge et al., 2013). CM is an important point of regulation for maintaining the correct balance of AAA in the cell. A protein-folding structural classification separates the CMs into three classes: the AroQ prokaryotic type, the AroQ eukaryotic type, and AroH, the latter two being present in monofunctional CMs. It is known that the CM of plants and eukaryotic microorganisms such as Saccharomyces cerevisiae belong to the monofunctional AroQ class and that they exhibit allosteric inhibition through Tyr and/or Phe and allosteric activation by $\operatorname{Trp}$ (Gu et al., 1997; Krappmann et al., 1999; Tzin and Galili, 2010). It has been described that Ustilago maydis also secretes a monofunctional aroQ CM lacking allosteric regulation that acts as a metabolic effector in favor of this pathogen during the colonization of maize plants (Djamei et al., 2011).

In this study we describe the characterization of the Tparo7 gene that encodes a $\mathrm{CM}$ in $T$. parareesei. Tparo7-silenced mutants were used to study the role of this primary and secondary metabolic node in $T$. parareesei biocontrol activity and its interaction with tomato plants in terms of root colonization and the induction of systemic defenses.

\section{MATERIALS AND METHODS}

\section{Microorganisms and Plants}

Escherichia coli DH5 $\alpha$ was used as a host for plasmid construction and propagation. This bacterial strain was grown in LuriaBertani (LB) broth or on LB plates, supplemented with ampicillin $(100 \mu \mathrm{g} / \mathrm{ml}), X$-gal $(40 \mu \mathrm{g} / \mathrm{ml})$, and IPTG $(10 \mu \mathrm{g} / \mathrm{ml})$, when required.

T. parareesei (formerly T. reesei) IMI 113135 (CABI Bioscience, Egham, UK), referred to here as the T6 strain, was used as the wild-type (WT) throughout this study. T6 was used as a source of DNA to clone the Tparo7 gene and also as a host in the transformation experiments to silence the Tparo7 gene. All strains were propagated on potato dextrose agar (PDA, Difco Laboratories, Detroit).

Fusarium oxysporum CECT 2866 (Spanish Type Culture Collection, Valencia, Spain) (FO), Rhizoctonia solani strain19 (RS), belonging to the anastomosis group AG-2-2 IIIB, and Botrytis cinerea $\mathrm{B} 05.10$ (BC) were used as plant pathogenic microorganisms in antagonism assays. $\mathrm{BC}$ was used as pathogen in in vivo assays. These strains were stored at $-80^{\circ} \mathrm{C}$ in $30 \%$ glycerol (FO, BC) and at $4^{\circ} \mathrm{C}$ in PDA plugs suspended in sterile water (RS).

Tomato seeds (Solanum lycopersicum "Marmande") were sterilized in $2 \%$ sodium hypochlorite for $20 \mathrm{~min}$ and washed thoroughly in sterile distilled water before use.

\section{Culture Conditions}

For gene expression and CM activity studies, T. parareesei mycelia were obtained following a two-step liquid culture procedure (Cardoza et al., 2006). First, the strains were grown in potato dextrose broth (PDB, Difco Laboratories) at $28^{\circ} \mathrm{C}$ and $200 \mathrm{rpm}$ for $48 \mathrm{~h}$. The fungal biomass was harvested, washed and transferred to minimal medium (MM) with $2 \%$ glucose as the 


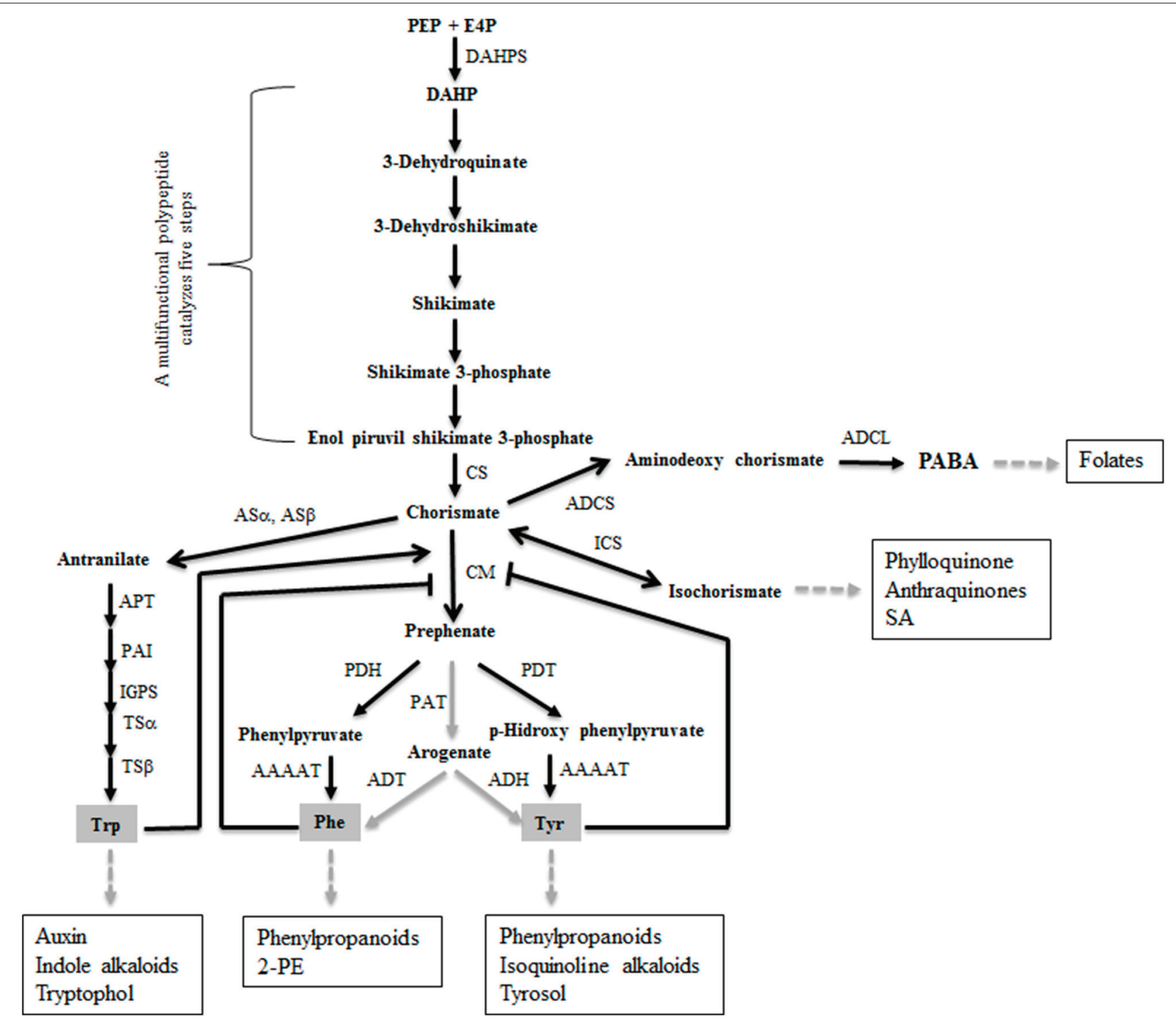

FIGURE 1 | Enzymes and metabolites comprising the shikimate pathway in Trichoderma. Black and gray arrows indicate the existence and absence, respectively, of genetic evidence (genes were identified in the available T. reesei genome and/or previously reported steps in yeast) for a given reaction. For simplicity, the AROM protein catalyzing the steps two to six is not shown. Abbreviations: PEP, phosphoenolpyruvic acid; E4P, erytrose 4-phosphate; DAHP,

3-deoxy-D-arabino-heptulosonate 7-phosphate; DAHPS, DAHP synthase; CS, chorismate synthase; CM, chorismate mutase; PDH, prephenate dehydrogenase; PDT, prephenate dehydratase; AAAAT, aromatic amino acid amidotransferase; AS $\alpha$, antranilate synthase alpha subunit; AS $\beta$, antranilate synthase beta subunit; PAT, prephenate aminotransferase; ADT, arogenate dehydratase; ADH, arogenate dehydrogenase; APT, antranilate phosphoribosyl transferase; PAI,

phosphoribosylantranilate isomerase; IGPS, indole-3-glycerol phosphate synthase; TS $\alpha$, tryptophan synthase alpha subunit; TS $\beta$, tryptophan synthase beta subunit; ICS, isochorismate synthase; ADCS, 4-amino-4-deoxychorismate synthase; ADCL, adenylsuccinate lyase; 2-PE, 2-phenylethanol; SA, salicylic acid; PABA, p-amino-benzoic acid. Major metabolites derived from the shikimate pathway are marked in squared boxes.

carbon source (Penttilä et al., 1987), and used as the control condition, or MM supplemented with $5 \mathrm{mM}$ Tyr, Phe, Trp, or chorismic acid barium salt, when indicated, or PDB. After $24 \mathrm{~h}$ of incubation at $28^{\circ} \mathrm{C}$ and $200 \mathrm{rpm}$, mycelia were collected by filtration, thoroughly washed with sterile water, lyophilized, and kept at $-80^{\circ} \mathrm{C}$ until RNA extraction.

For the determination of growth rates, fungi were inoculated at the center of MM or PDA plates and colony diameters were recorded every $24 \mathrm{~h}$. To test the influence of different carbon and nitrogen sources on fungal growth, MM (with $2 \%$ glucose) or $\mathrm{MM}$ in which $2 \%$ glucose was replaced by $2 \%$ glycerol containing or not $38 \mathrm{mM}$ ammonium sulfate or $5 \mathrm{mM}$ Tyr, $5 \mathrm{mM}$ Phe, and $2 \mathrm{mM}$ Trp, were also used. For the determination of fungal biomass after growth in liquid culture, mycelium was collected by filtration, lyophilized and the dry weight was measured. 
For the analysis of hydrolytic activities, intracellular proteins were extracted from mycelia of $T$. parareesei strains obtained from PDB containing $0.5 \% R$. solani cell walls (RS-CWs) grown at $28^{\circ} \mathrm{C}$ and $200 \mathrm{rpm}$ for $48 \mathrm{~h}$. RS-CWs were obtained as previously described (Fleet and Phaff, 1974), using fungal mycelium from a $\mathrm{PDB}$ culture incubated at $25^{\circ} \mathrm{C}$ and $200 \mathrm{rpm}$ for 4 days.

For metabolite quantification, T. parareesei supernatants were obtained from MM or PDB cultures incubated at $28^{\circ} \mathrm{C}$ and $200 \mathrm{rpm}$ for $48 \mathrm{~h}$.

To perform plant rhizosphere colonization tests, eight tomato seeds were grown in a Phytatray II box (Sigma-Aldrich) containing $100 \mathrm{ml}$ of liquid MS medium (Murashige and Skoog, 1962) supplemented with $1 \%$ sucrose for 2 weeks. Each box was inoculated with $10^{5}$ conidial germlings $\mathrm{ml}^{-1}$ of $T$. parareesei strain or not (control). The collection of germlings and the maintenance of plant-fungal co-cultures were carried out as previously described (Rubio et al., 2014). After $48 \mathrm{~h}$ of plantfungal interaction, the roots from eight plants per treatment were collected, washed with distilled water, frozen, lyophilized, and kept at $-20^{\circ} \mathrm{C}$ until total DNA extraction. Three independent tomato-T. parareesei co-culture experiments were used for each fungal strain.

\section{DNA and RNA Procedures}

Total DNAs from fungi were extracted following the method of Raeder and Broda (Raeder and Broda, 1985), using mycelium collected from a PDB culture incubated at $28^{\circ} \mathrm{C}$ and $200 \mathrm{rpm}$ for 2 days. DNA isolation from tomato roots was performed with the cetyltrimethylammonium bromide (CTAB) extraction method (Dellaporta et al., 1983). Total RNA was extracted using TRIZOL $^{\circledR}$ reagent (Invitrogen Life Technologies, Carlsbad), following the instructions of the manufacturer.

For Southern analyses, $10 \mu \mathrm{g}$ of genomic DNA was SacIdigested, electrophoresed on a $0.7 \%$ agarose gel and transferred to a Hybond- $\mathrm{N}^{+}$membrane (Amersham Biosciences AB, Uppsala, Sweden). The phleomycin gene was labeled using the DIG High Prime kit (Roche, Penzberg, Germany), following the manufacturer's instructions, and used as probe. Hybridization, washes and detection were carried out as previously described (Tijerino et al., 2011).

\section{Construction of the Gene-silencing Vector and Transformation}

Plasmid pSIL (Cardoza et al., 2006) was linearized with SpeIBamHI and then ligated to a 500-bp SpeI-BamHI fragment of the Tparo7 gene. This fragment was in "sense" relative to the orientation of the ta gene promoter from T. harzianum. The construct was then linearized with HindIII-XhoI and ligated to the same 500-bp Tparo7 fragment but in an "antisense" orientation relative to the $t a$ gene promoter. A 159-bp intron was introduced between both the sense and antisense fragments of the Tparo7 gene. The resulting plasmid also contained the terminator region of the $c b h 2$ gene from $T$. reesei and was designated PSILARO7. In order to transform this cassette in T. parareesei T6, pSIL-ARO7 was digested with SacI to isolate the SIL-Tparo7 fragment, which was then ligated to the same restriction site of plasmid pJL43b1 (Gutiérrez et al., 1997), giving rise to the final construct, pJL43b1-ARO7 (7.6 kb). This latter vector was used to transform $T$. parareese $i$ T6 by a protoplast-based method described previously (Cardoza et al., 2006). In parallel, strain T6 was also transformed with pJL43b1 to obtain empty vector transformants; one of them, Tp-TC, was included in the assays as a transformation control. Transformants were selected for phleomycin resistance.

\section{Real-time PCR Analysis}

Gene expression was analyzed by quantitative real-time PCR. cDNA was synthesized from $2 \mu \mathrm{g}$ of RNA, which was treated with DNase RQ1 (Promega Biotech Ibérica, Alcobendas, Spain) and then used for reverse transcription with an oligo(dT) primer with the Transcriptor First Strand cDNA Synthesis kit (Takara Inc., Tokyo, Japan), following the manufacturer's protocol. Real-time PCR reactions were performed with a StepOnePlus thermocycler (Applied Biosystems, Applied Foster City) in a total volume of $10 \mu \mathrm{l}$, using SYBR FAST KAPA qPCR (Biosystems, Buenos Aires, Argentina) and a final primer concentration of $100 \mathrm{nM}$ each. Reactions were performed with cDNA from four pooled biological replicates for each condition, with the exception of five pooled biological replicates used to analyze plant defense gene expression from in vivo cultures. All reactions were performed in triplicate under the following conditions: an initial denaturation step $\left(10 \mathrm{~min}\right.$ at $95^{\circ} \mathrm{C}$ ) followed by 40 cycles of denaturation $\left(30 \mathrm{~s}\right.$ at $\left.95^{\circ} \mathrm{C}\right)$, annealing $\left(1 \mathrm{~min} 60^{\circ} \mathrm{C}\right)$, and extension $(1 \mathrm{~min}$ $\left.72^{\circ} \mathrm{C}\right)$. CT values were calculated using the Applied Biosystems software, and transcript abundance was calculated with Microsoft Excel from Ct (cycle threshold) values normalized to the actin gene signal. The slopes and efficiency for each primer pair, Qaro7-C/Qaro7-D, and Act-F/Act-R, were measured for dilution series of pooled cDNA samples and calculated using the Applied Biosystems software (Table S1). Relative expression levels were calculated using the ${ }^{-} \Delta \Delta \mathrm{CT}$ method (Livak and Schmittgen, 2001).

DNA quantification of wild-type, Tp-TC and Tparo7-silenced transformants from colonized tomato roots was performed by real-time PCR as previously described (Morán-Diez et al., 2009), using the primer couples Act-tomF/Act-tomR and Act-F/Act-R (Table S1) to amplify a fragment of the actin gene from tomato and Trichoderma, respectively. Mixture and real-time PCR conditions were as indicated above. Ct values were calculated and the amount of fungal DNA was estimated using standard curves. Values were normalized to the amount of tomato DNA in the samples. Each sample was tested in triplicate.

\section{Activity Assays}

Mycelia collected from liquid cultures, grown as described above, were lyophilized and homogenized in $100 \mathrm{mM}$ Tris- $\mathrm{HCl}(\mathrm{pH}$ 7.5) plus $10 \%$ sodium dodecyl sulfate $(\mathrm{w} / \mathrm{v})$ buffer at $800 \mathrm{rpm}$ for $1 \mathrm{~h}$ at $4{ }^{\circ} \mathrm{C}$ in a Thermomixer (Eppendorf). Protein extracts were recovered by centrifugation at $12000 \times$ g at $4^{\circ} \mathrm{C}$ for $20 \mathrm{~min}$ and stored at $-20^{\circ} \mathrm{C}$. Quantitative protein determination was performed with the Bradford assay (Bradford, 1976) with bovine serum albumin (BSA) as standard protein.

CM activity was determined spectrophotometrically based on the formation of phenylpyruvate by treatment with 
$\mathrm{HCl}$ (Davidson and Hudson, 1987). The reaction mixture contained $1 \mathrm{mM}$ chorismate, $0.1 \mathrm{mg} / \mathrm{ml} \mathrm{BSA}$, and $10 \mathrm{mM} \mathrm{2-}$ mercaptoethanol in $50 \mathrm{mM}$ Tris- $\mathrm{HCl}$ buffer with $1 \mathrm{mM}$ EDTA, $\mathrm{pH}$ 8.0. For the CM activity assay, $0.4 \mathrm{ml}$ of this solution was preheated for $5 \mathrm{~min}$ at $37^{\circ} \mathrm{C}$ in a water bath. After the addition of $50 \mu \mathrm{l}$ of enzyme solution, the reaction was incubated at $37^{\circ} \mathrm{C}$ for $5 \mathrm{~min}$. For the conversion of chorismate to phenylpyruvate, $0.4 \mathrm{ml}$ of $1 \mathrm{M} \mathrm{HCl}$ was added and the mixture was further incubated at $37^{\circ} \mathrm{C}$ for $10 \mathrm{~min}$. The samples were rendered alkaline with $1 \mathrm{ml}$ of $2.5 \mathrm{M} \mathrm{NaOH}$, and absorbance was measured at $320 \mathrm{~nm}$ against a blank sample without enzyme. Protease and chitinase activities were determined in colorimetric assays as previously described (Montero-Barrientos et al., 2011), measuring the hydrolysis of azocasein at $366 \mathrm{~nm}$ (Holwerda and Rogers, 1992), and the release of $\mathrm{N}$-acetylglucosamine during the hydrolysis of chitin at $585 \mathrm{~nm}$ (Reissig et al., 1955), respectively. All activity measurements were performed in triplicate. Activities



\section{Quantification of Metabolites}

One hundred $\mathrm{ml}$ of culture supernatant was collected by filtration through sterile filter paper and lyophilized. Then, the resulting powder was extracted with $1 \mathrm{ml}$ of a $\mathrm{H}_{2} \mathrm{O}$ :methanol solution (9:1) and filtered through a $0.22-\mu \mathrm{m}$ membrane. Tyrosol and 2-PE quantifications were carried out at the Mass Spectrometry Service of NUCLEUS (University of Salamanca) by capillary gas chromatography-mass spectrometry using an Agilent GC7890A gas chromatograph with a MS220 detector. A VF5ms capillary column was used $(30 \mathrm{~m}, 0.25 \mathrm{~mm} 0.25$ micron), with a starting temperature of $50^{\circ} \mathrm{C}$ kept for $5 \mathrm{~min}$, followed by a ramp at $5^{\circ} \mathrm{C}$ per min up to $270^{\circ} \mathrm{C}$, this temperature being held for $5 \mathrm{~min}$.

Salicylic acid (SA) production was determined in $4 \mathrm{ml}$ of culture supernatants as previously described (Leeman et al., 1996; Mercado-Blanco et al., 2001).

\section{In Vitro Antifungal Assays}

Confrontation assays (dual cultures) between $T$. parareesei strains and RS, FO, or BC plant pathogens were carried out in triplicate as previously described (Rubio et al., 2009). The dual cultures were photographed after 4 days at $28^{\circ} \mathrm{C}$. BC dual cultures were also photographed after 18,48 , and $72 \mathrm{~h}$ at $28^{\circ} \mathrm{C}$.

Growth assays on cellophane sheets were carried out in triplicate, as previously described (Rubio et al., 2009). Growth diameters were measured after $72 \mathrm{~h}$ for RS, $96 \mathrm{~h}$ for BC and after $120 \mathrm{~h}$ for FO. The results are expressed as the percentage of growth inhibition of each pathogen by each $T$. parareesei strain with respect to the mean colony diameters of each pathogen in control cultures.

The antifungal activity of $T$. parareesei supernatants against FO and BC was tested. A conidial suspension (2000 conidia in $5 \mu \mathrm{l}$ ) was added to the wells of sterile 96-well flat-bottomed microtiter plates along with $50 \mu \mathrm{l}$ of water (control) or filtersterilized $(0.22-\mu \mathrm{m}$ syringe filter; Millipore) supernatant from a 48 h-PDB culture, previously boiled for $10 \mathrm{~min}$ to avoid interference of enzymatic activities, or unboiled. PDB medium was added to each well up to a final volume of $150 \mu$ l. The plates were shaken briefly and placed in the dark at $28^{\circ} \mathrm{C}$ for $72 \mathrm{~h}$.
FO and BC growth were determined at $0,24,48$, and $72 \mathrm{~h}$ by measuring optical density at $595 \mathrm{~nm}$ using a Sunrise microtiter plate reader (Tecan Ibérica, Barcelone, Spain). Each test was performed in sixtuplicate.

\section{In Vivo Assays}

Tomato seeds were coated with a conidial suspension containing $2 \times 10^{8}$ conidia/ml of T. parareesei T6, Tp-TC, or Tparo7-silenced transformants Tparo7-S3 and Tparo7-S4, or not (control) and were left in open Petri dishes to air-dry overnight in a laminar flow hood. One $\mathrm{ml}$ was used to coat 40 seeds. Plants were maintained under greenhouse conditions with a photoperiod of $16 \mathrm{~h}$ light: $8 \mathrm{~h}$ dark, a temperature between 18 and $30^{\circ} \mathrm{C}$, and humidity maintained at $75 \%$ for 4 weeks. At this time, measurements of stem height and stem diameter were manually taken. Aboveground and root tissues were separated and dried until constant weight. Chlorophyll values were obtained with a Chlorophyll meter SPAD-502 Plus (Konica Minolta, Japan). The sensitivity of 4-week-old tomato plants to BC was evaluated. One leaf from each plant was inoculated on three leaflets, using $10 \mu \mathrm{l}$ of a germination solution $(20 \mathrm{mM}$ glucose and $20 \mathrm{mM}$ potassium phosphate) containing 2500 conidia per point. Necrotic leaf area was evaluated after three days using ImageJ free software. Ten plants were considered for each condition.

The aerial part of each tomato plant was sampled before being infected with BC and used for RNA extraction. Marker genes representative of the SA [pathogenesis-related protein $1(P R-1)$ ], jasmonic acid (JA) [lipoxygenase 1 (LOX1)] and ethylene (ET) [ethylene-insensitive protein 2 (EIN2)] signaling pathways were analyzed using real-time PCR, as described above. The primer pairs used are shown in Table S1.

\section{Sequence Analyses}

Sequences were analyzed using the DNAstar package (Lasergene, Madison). Protein sequences were aligned using the CLUSTAL X algorithm (Thompson et al., 1994). The nucleotide sequence of Tparo 7 was deposited in the GenBank database with Accession No. KT240045.

\section{Statistical Analyses}

Analysis of variance (ANOVA) was conducted with SPSS v. 19 software (SPSS Inc., Chicago) and Tukey's test was used at the 95\% significance level.

\section{RESULTS}

\section{Isolation and Expression of the Tparo7 Gene}

A gene encoding a putative CM was identified in the available T. reesei genome (http://genome.jgi-psf.org/Trire2/Trire2.home. html). Based on its genomic sequence, two oligonucleotides were designed, Tparo7-F and Tparo7-R, and used to amplify a 974-bp fragment from T. parareesei T6 genomic DNA by PCR. This 974bp fragment had an open reading frame (ORF) of $801 \mathrm{bp}$, two introns of 82 and $91 \mathrm{bp}$, and it was designated Tparo7. The ORF 
of Tparo7 encodes a protein of 266 amino acids with a theoretical molecular mass of $23.94 \mathrm{kDa}$ and an isoelectric point of 5.44 . An analysis of the primary structure of TpARO7 revealed the conserved monofunctional aroQ eukaryotic-type CM domain from position 14-262, related to its catalytic mechanism. There was also similarity of the deduced TpARO7 sequence to cytosolic CMs from other filamentous (AROC of Aspergillus nidulans, $60 \%$ identity) or yeast (ARO7 of S. cerevisiae, $46 \%$ identity) ascomycetes, basidiomycetes (ARO7 of $U$. maydis, $40 \%$ identity), plants (Arabidopsis thaliana, 37-41\%) or bacteria (Chitinovibrio alkaliphilus, 37\% identity). Sequence similarity was lower with the secreted Cmul of $U$. maydis (12\%). A secondary structure analysis of TpARO7 predicted the prevalence of the alpha-helix conformation.

The allosteric regulation effect by AAA was explored in intracellular proteins, obtained from T6 mycelia, measuring CM activity after incubation in the presence of $100 \mu \mathrm{M}$ Tyr, Phe, or Trp, or a mixture of these three AAA at a concentration of $100 \mu \mathrm{M}$ each. In comparison with the control condition, a $38 \%$ reduction in CM activity was recorded when $100 \mu \mathrm{M}$ Tyr was added to the reaction mixture, whereas an activity increase of $20 \%$ was detected with $100 \mu \mathrm{M}$ Trp. No significant changes in

TABLE 1 | Chorismate mutase activity of $T$. parareesei T6 intracellular protein extracts.

\begin{tabular}{lc}
\hline & $\begin{array}{c}\text { Mean CM activity } \\
\left(\mu \text { mol } \cdot \mathbf{m i n}^{-1} / \mathbf{m g} \text { protein }\right) \pm S \boldsymbol{D}\end{array}$ \\
\hline MM-glucose & $1.20 \pm 0.09^{\mathrm{a}}$ \\
MM-Tyr & $1.02 \pm 0.02^{\mathrm{ab}}$ \\
MM-Phe & $0.90 \pm 0.10^{\mathrm{b}}$ \\
MM-Trp & $1.12 \pm 0.09^{\mathrm{ab}}$ \\
MM-chorismic acid & $0.85 \pm 0.02^{\mathrm{b}}$ \\
\hline
\end{tabular}

Values are means of three replicates with the corresponding standard deviations. Values followed by different superscript letters are significantly different $(P<0.05)$. Activity was measured in mycelia from $24 \mathrm{~h} \mathrm{MM}$ supplemented with $2 \%$ glucose or $5 \mathrm{mM}$ Tyr, Phe, Trp, or chorismic acid barium salt cultures.
CM activity were observed when Phe or the AAA mixture was added.

Tparo7 expression was investigated using real-time PCR after growing $\mathrm{T} 6$ for $24 \mathrm{~h}$ in the presence of $5 \mathrm{mM}$ chorismic acid or each AAA-Tyr, Phe, or Trp. All these compounds upregulated Tparo7 expression as compared with the transcript levels detected in 24-h MM-grown mycelia (control condition) (Figure S1). However, compared with the CM activity detected in MM, lower values were recorded from T6 cultures supplemented separately with these four compounds (Table 1).

\section{Isolation of Tparo7-silenced Transformants}

In order to characterize the Tparo7 gene functionally, plasmid p43b1-ARO7 was constructed and transformed in T. parareesei T6. Eight out of fourteen transformants showing phleomycin resistance were checked by PCR using the primers TADIR2 and Intro-R. The presence of a 1200-bp amplification fragment was observed for seven of them. Integration of the transformation cassette was analyzed by Southern blot using phleomycin cDNA as a probe (Figure S2). Strains Tparo7-S2, Tparo7-S3, and Tparo7-S4, representing the three different integration patterns found among these seven transformants, and the transformation control strain Tp-TC, were chosen for further studies.

We analyzed both the expression of the Tparo7 gene and CM activity in the selected transformants under two different culture conditions, using the expression level in strain T6 as a reference condition. The Tparo7-S3 and Tparo7-S4 transformants showed significantly lower Tparo7 transcript levels linked to lower CM activity than those detected in T6 or Tp-TC after $24 \mathrm{~h}$ growth in $\mathrm{MM}$ and $\mathrm{PDB}$ (Figure 2, Table 2). Taking into account that Tparo7-S2 showed higher Tparo7 transcript levels and CM activity than T6 or Tp-TC in PDB, the Tparo-S3 and TparoS4 strains were selected as Tparo7-silenced transformants for inclusion in ensuing assays. Since lower Tparo7 expression levels were accompanied by lower CM activity, this gene must encode a CM enzyme in $T$. parareesei.

$\mathrm{CM}$ constitutes a central node of primary metabolism. Thus, the silenced transformants displayed lower growth rates than the
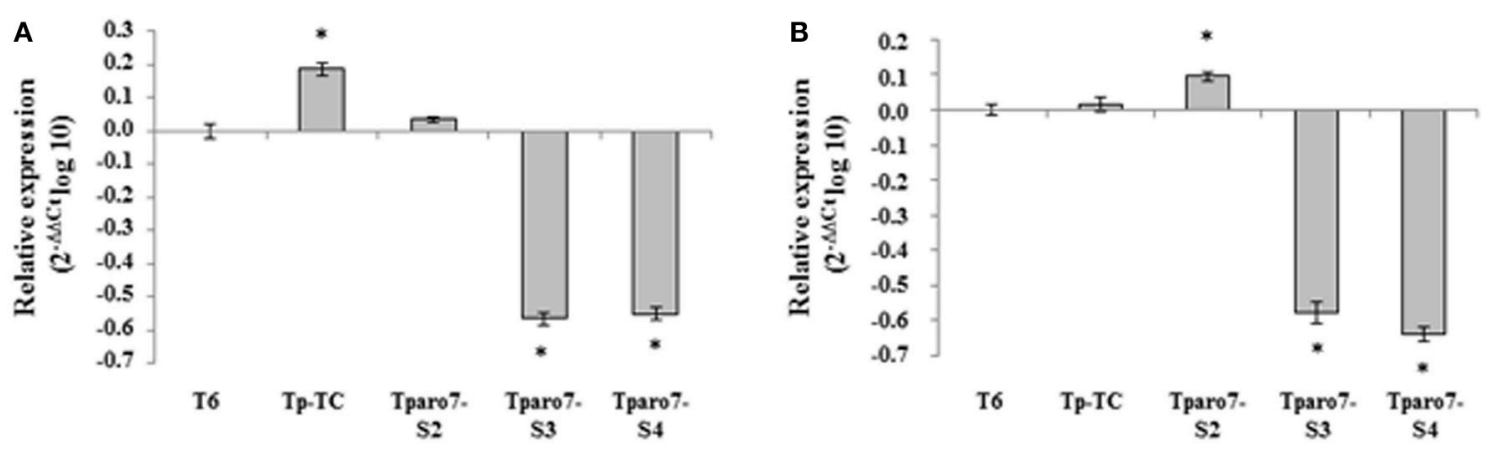

FIGURE 2 | Quantification of Tparo7 transcripts in a control transformant (Tp-TC) and three silenced transformants (Tparo7-S2, Tparo7-S3 and Tparo7-S4) by real-time PCR. Values correspond to relative measurements against the Tparo7 transcript in the wild-type $T$. parareesei T6 (2 $-\Delta \Delta$ Ct $=1$ ). The experiment was carried out with mycelia grown for $48 \mathrm{~h}$ on PDB and transferred to MM containing $2 \%$ glucose (A) or PDB (B) for $24 \mathrm{~h}$. T. parareesei T6 actin was used as an internal reference gene. Bars represent the standard deviations of the mean of three replicates. Asterisk (*) represents statistically significant differences $(P<0.05)$. 
T6 and Tp-TC control strains in all the different culture media tested (Table 3). In addition, Tparo7-silenced transformants showed lower sporulation but a higher production of diffusible pigments on PDA. All strains displayed the highest colony

TABLE 2 | Chorismate mutase activity of T. parareesei T6, transformation control Tp-TC, or silenced-transformant intracellular protein extracts.

\begin{tabular}{lcc}
\hline & \multicolumn{2}{c}{ Mean CM activity } \\
& \multicolumn{2}{c}{$\left(\mu \mathrm{mol} \mathrm{min}^{-1} / \mathrm{mg}\right.$ protein $) \pm \mathbf{S D}$} \\
\cline { 2 - 3 } & $\mathbf{M M}$ & PDB \\
\hline T6 & $1.87 \pm 0.09^{\mathrm{b}}$ & $0.41 \pm 0.01^{\mathrm{b}}$ \\
Tp-TC & $2.50 \pm 0.68^{\mathrm{a}}$ & $0.33 \pm 0.02^{\mathrm{c}}$ \\
Tparo7-S2 & $1.78 \pm 0.06^{\mathrm{b}}$ & $0.49 \pm 0.03^{\mathrm{a}}$ \\
Tparo7-S3 & $0.70 \pm 0.03^{\mathrm{C}}$ & $0.23 \pm 0.02^{\mathrm{d}}$ \\
Tparo7-S4 & $0.08 \pm 0.05^{\mathrm{d}}$ & $0.08 \pm 0.02^{\mathrm{e}}$
\end{tabular}

Values are means of three replicates with the corresponding standard deviations. For each medium, values followed by different superscript letters are significantly different $(P$ $<0.05)$. Activity was measured in mycelia from $24 \mathrm{~h} \mathrm{MM}$ supplemented with $2 \%$ glucose or PDB cultures.

TABLE 3 | Growth rates of T. parareesei strains on different culture media.

\begin{tabular}{lcccc}
\hline & PDA & MM-glucose & MM-glycerol & MM-glycerol-AAA \\
\hline T6 & $7.0 \pm 0.1^{\mathrm{a}}$ & $4.2 \pm 0.0^{\mathrm{a}}$ & $3.8 \pm 0.1^{\mathrm{a}}$ & $3.0 \pm 0.1^{\mathrm{a}}$ \\
Tp-TC & $7.0 \pm 0.1^{\mathrm{a}}$ & $4.1 \pm 0.1^{\mathrm{a}}$ & $3.9 \pm 0.1^{\mathrm{a}}$ & $3.2 \pm 0.2^{\mathrm{a}}$ \\
Tparo7-S3 & $4.2 \pm 0.0^{\mathrm{c}}$ & $1.9 \pm 0.1^{\mathrm{b}}$ & $1.5 \pm 0.2^{\mathrm{c}}$ & $0.7 \pm 0.2^{\mathrm{b}}$ \\
Tparo7-S4 & $5.0 \pm 0.3^{\mathrm{b}}$ & $2.0 \pm 0.1^{\mathrm{b}}$ & $1.9 \pm 0.0^{\mathrm{b}}$ & $0.9 \pm 0.1^{\mathrm{b}}$
\end{tabular}

*The ammonium sulfate of the MM was replaced by a mix containing $5 \mathrm{mM} T \mathrm{Tr}, 5 \mathrm{mM}$ Phe, and $2 m M$ Trp.

Values are means of three replicates with the corresponding standard deviations. For each medium, values followed by different superscript letters are significantly different ( $P$ $<0.05$ ). Colony diameters (cm per $24 \mathrm{~h}$ ) of wild-type (T6), transformation control (Tp-TC) and Tparo7-silenced transformants (Tparo7-S3 and Tparo7-S4) were measured on agar plates containing PDA or MM supplemented with $2 \%$ glucose or $2 \%$ glycerol. diameters at $37^{\circ} \mathrm{C}$, the optimal growth temperature for $T$. parareesei, and significantly lower sizes were observed in the silenced mutants in comparison with those from T6 and Tp-TC (data not shown).

\section{Antifungal Activity}

The influence of Tparo7 silencing in the antifungal activity of $T$. parareesei was evaluated using different in vitro assays with the phytopathogens FO, BC and/or RS as targets. A lower mycoparasitic behavior was observed for Tparo7-silenced transformants than for T6 or Tp-TC in dual confrontation experiments performed between the $T$. parareese $i$ strains and the three targets (Figure 3 and Figure S3). After 4 days of incubation, T6 and Tp-TC were able to overgrow the colonies of FO or BC, whereas Tparo7-S3 and Tparo7-S4 only surrounded them. This absence of FO and BC overgrowth capacity by the silenced transformants persisted even at 10 days of incubation (data not shown).

The antagonistic potential of $T$. parareesei extracellular compounds against these pathogens was evaluated using a membrane assay. After removal of the cellophane sheet containing the $T$. parareesei mycelium, the effect of the total compounds secreted by antagonistic strains on the growth of pathogens was determined. The FO, RS, and BC growth inhibition percentages calculated for the four T. parareesei strains are summarized in Table 4. The compounds secreted by T6 or Tp-TC displayed a more marked inhibition of FO and RS than those secreted by Tparo7-silenced mutants $(P<0.05)$. However, the highest and the lowest inhibition values of $\mathrm{BC}$ were respectively obtained from plates where strains Tparo7-S3 and Tparo-S4 had been previously grown.

To analyze the effect of Tparo7 silencing in the production of CW hydrolytic enzymes by $T$. parareesei strains, we measured protease and chitinase activities on intracellular proteins from 48-h PDB plus $0.5 \%$ RS-CWs-grown mycelium (Table 5). Lower values of protease activity were observed for the silenced transformants Tparo7-S3 and Tparo7-S4 than for strains T6
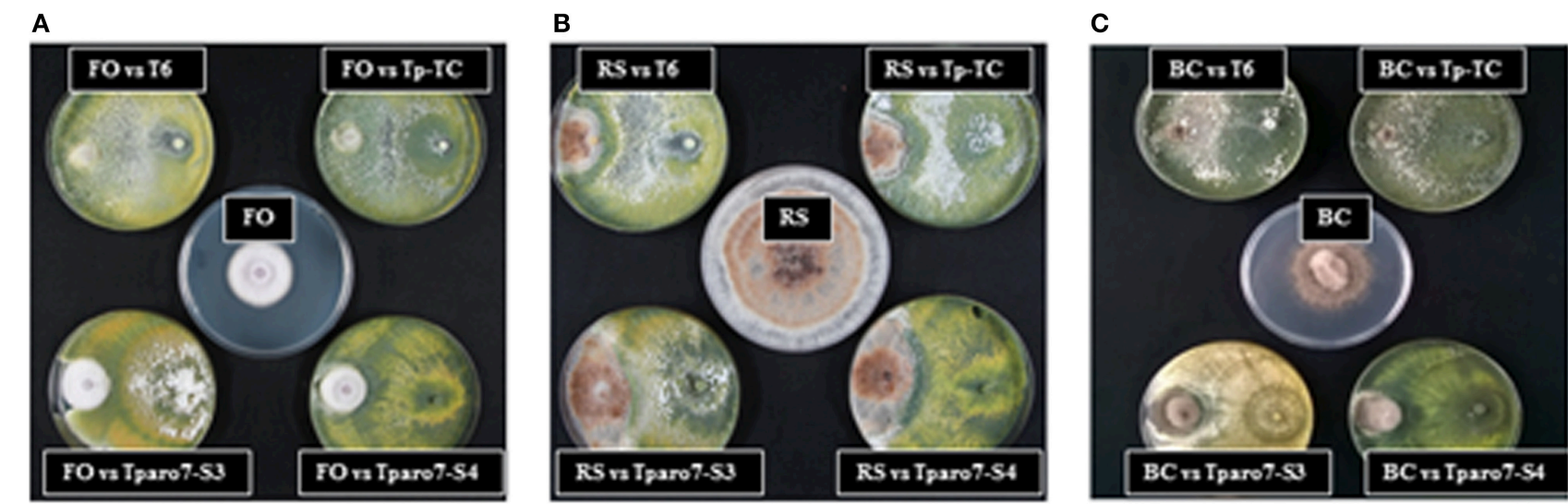

FIGURE 3 | Dual cultures of strains T6, the silenced transformants Tparo7-S3 and Tparo7-S4, and the control transformant Tp-TC of T. parareesei and the pathogens F. oxysporum (FO) (A), R. solani (RS) (B), and B. cinerea (BC) (C) on PDA medium. Plates in the center correspond to the growth of each pathogen without Trichoderma strains. Plates were incubated at $28^{\circ} \mathrm{C}$ for 4 days. 
or Tp-TC, although such differences were only significant for Tparo7-S4 $(P<0.05)$. However, strain Tparo7-S3 displayed significantly higher chitinase activity than any other strain.

The antifungal activity of $T$. parareesei supernatants was evaluated against $\mathrm{FO}$ and $\mathrm{BC}$ on 96-well $\mathrm{E}$ plates. In these tests, the hyphal growth from conidia of the two target fungi was registered at 24,48 , and $72 \mathrm{~h}$, and unboiled and boiled supernatants were considered to determine the antifungal activity

TABLE 4 | Colony growth inhibition (\%) of $F$. oxyxporum, $R$. solani and $B$. cinerea by $T$. parareesei strains grown on cellophane membranes.

\begin{tabular}{lccr}
\hline & F. oxyxporum & R. solani & B. cinerea \\
\hline T6 & $28.3 \pm 0.4^{\mathrm{a}}$ & $24.0 \pm 0.0^{\mathrm{a}}$ & $22.7 \pm 1.7^{\mathrm{c}}$ \\
Tp-TC & $28.1 \pm 0.4^{\mathrm{a}}$ & $24.0 \pm 0.2^{\mathrm{a}}$ & $26.2 \pm 0.8^{\mathrm{b}}$ \\
Tparo7-S3 & $26.2 \pm 0.3^{\mathrm{b}}$ & $11.0 \pm 0.1^{\mathrm{b}}$ & $29.8 \pm 0.2^{\mathrm{a}}$ \\
Tparo7-S4 & $16.0 \pm 0.1^{\mathrm{c}}$ & $2.0 \pm 0.1^{\mathrm{c}}$ & $8.5 \pm 0.5^{\mathrm{d}}$ \\
\hline
\end{tabular}

Values are means of three replicates with the corresponding standard deviations. For each column, values followed by different superscript letters are significantly different $(P<$ 0.05). Strains were wild-type (T6), transformantion control (Tp-TC), and Tparo7-silenced transformants (Tparo7-S3 or Tparo7-S4). of SMs plus secreted enzymes and SMs, respectively (Figure 4). The absorbance values recorded at $0 \mathrm{~h}$ did not show significant differences among the five conditions considered in these tests (data not shown). The supernatants from the different $T$. parareesei strains had significant antifungal activity against FO and $\mathrm{BC}$ at $72 \mathrm{~h}$. Moreover, Tparo7-S3 supernatants, unboiled and

TABLE 5 | Protease and chitinase activities measured in $T$. parareesei strain intracellular protein extracts obtained from $48 \mathrm{~h}$ liquid cultures in PDB supplemented with $0.5 \% R$. solani cell walls.

\begin{tabular}{lcc}
\hline & \multicolumn{2}{c}{ Mean activity } \\
& \multicolumn{2}{c}{$\left(\mu \mathrm{mol} \cdot \mathrm{min}^{-1} / \mathbf{m g}\right.$ protein $) \pm \mathbf{S D}$} \\
\cline { 2 - 3 } & Protease & Chitinase \\
\hline T6 & $56.83 \pm 0.67^{\mathrm{a}}$ & $0.78 \pm 0.09^{\mathrm{b}}$ \\
Tp-TC & $57.84 \pm 3.80^{\mathrm{a}}$ & $0.64 \pm 0.03^{\mathrm{c}}$ \\
Tparo7-S3 & $48.07 \pm 5.83^{\mathrm{ab}}$ & $1.93 \pm 0.25^{\mathrm{a}}$ \\
Tparo7-S4 & $24.65 \pm 0.88^{\mathrm{b}}$ & $0.90 \pm 0.07^{\mathrm{b}}$ \\
\hline
\end{tabular}

Values are means of three replicates with the corresponding standard deviations. For each activity, values followed by different superscript letters are significantly different $(P<0.05)$.

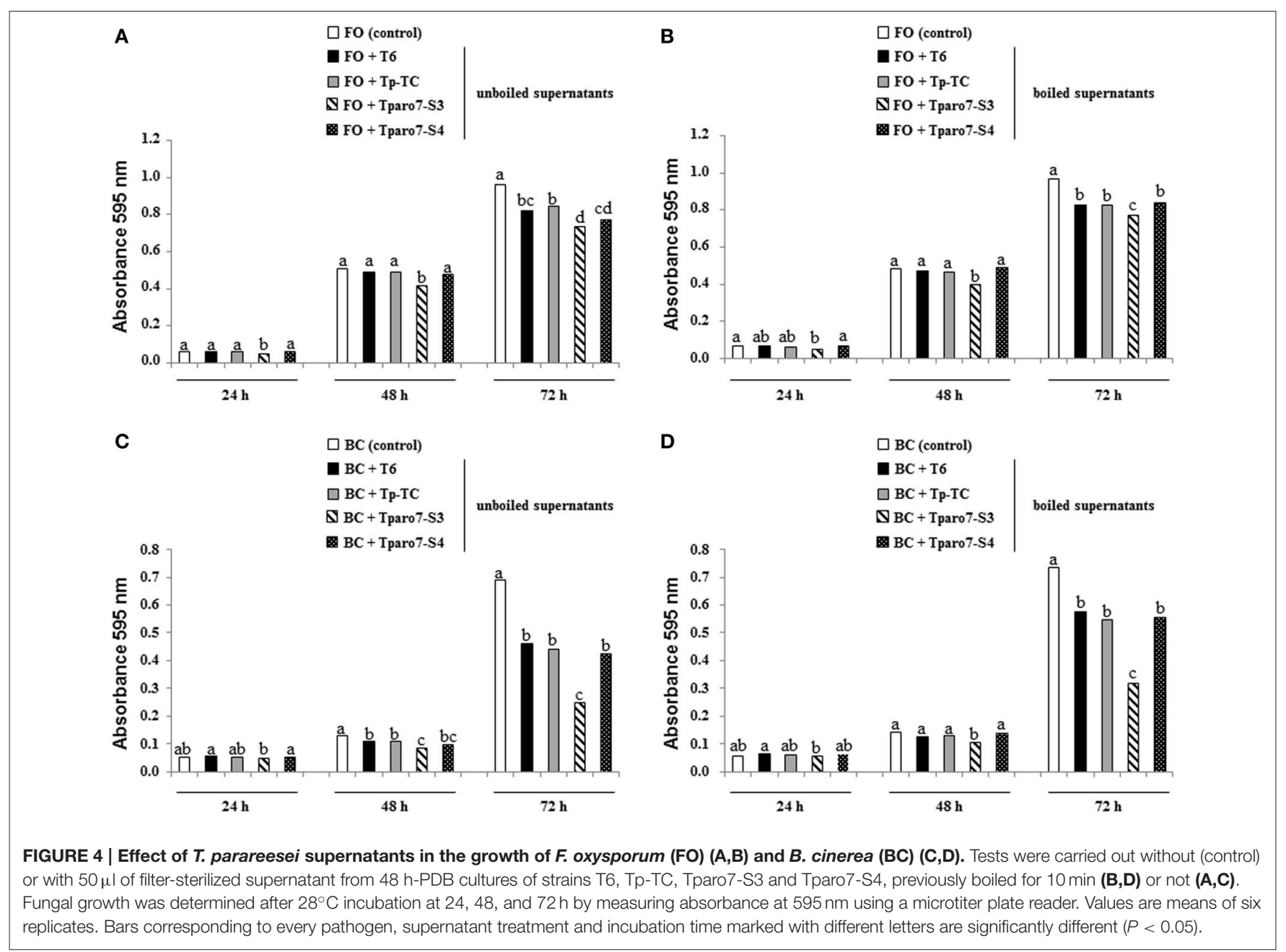


boiled, showed significant higher inhibitory effect against the two pathogens compared to that of T6 or Tp-TC supernatants at 48 and $72 \mathrm{~h}$. In a wide sense, $T$. parareese $i$ supernatants were more effective against $\mathrm{BC}$ and SMs looked to be more relevant for their antifungal activity against both pathogens.

\section{Metabolite Production}

To analyze the effect of Tparo7 silencing on shikimate pathway metabolite production, tyrosol, 2-PE and SA were determined in MM and PDB supernatants from 48-h-old cultures (Table 6). These metabolites were not detected in MM for any strain. Higher amounts of tyrosol, 2-PE and SA were measured in PDB supernatants of Tparo7-silenced transformants than those observed for T6 or Tp-TC. Similar results were obtained in two independent biological experiments.

In order to analyze the biocontrol potential of tyrosol, 2-PE and SA, putatively formed in the metabolic AAA pathway, we tested the effect of these compounds on the mycelial growth of $\mathrm{RS}, \mathrm{FO}$, and $\mathrm{BC}$. The growth inhibition percentages of FO, RS and $\mathrm{BC}$ by 5,10 , and $30 \mathrm{mM}$ of commercial tyrosol, 2-PE, or SA, concentrations no biologically relevant, are shown in Table S2. In general, growth inhibition values were directly proportional to the concentration of tyrosol, 2-PE, or SA in the culture medium. The growth of these plant pathogens was completely inhibited by $30 \mathrm{mM} 2-\mathrm{PE}$ or SA, and inhibition percentages of about $55 \%$ were obtained with $30 \mathrm{mM}$ tyrosol.

\section{Tomato Rhizosphere Colonization}

The role of Tparo7 in plant rhizosphere colonization was evaluated on tomato roots by quantitative real-time PCR using T6 and Tp-TC as controls and the two Tparo7-silenced transformants. As shown in Table 7, the amount of Tparo7S3 and Tparo7-S4 DNA obtained from tomato roots was significantly lower than those of strains T6 and Tp-TC $(P<$ 0.05).

\section{Biocontrol in Tomato}

Four-week-old tomato plants previously seed-coated with an aqueous solution (control) or treated with conidia of T6, Tp-TC, Tparo7-S3, or Tparo7-S4 were evaluated in this assay. The in vivo assay results revealed that there were significant differences in stem length, aboveground and root dry weights, chlorophyll

TABLE 6 | Concentration of tyrosol, 2-PE and SA in T. parareesei T6, $\mathrm{Tp}-\mathrm{TC}$, Tparo7-S3, and Tparo7-S4 strain supernatants obtained from $48 \mathrm{~h}$ PDB cultures.

\begin{tabular}{llccccc}
\hline & \multicolumn{2}{c}{ Tyrosol } & \multicolumn{2}{c}{ 2-PE } & \multicolumn{2}{c}{ SA } \\
\hline T6 & 18.98 & 19.04 & 9.49 & 9.52 & 0.09 & 0.12 \\
Tp-TC & 20.33 & 21.01 & 11.96 & 12.36 & 0.08 & 0.08 \\
Tparo7-S3 & 33.27 & 33.60 & 27.40 & 27.66 & 0.73 & 0.59 \\
Tparo7-S4 & 32.13 & 27.21 & 28.11 & 23.81 & 0.15 & 0.21 \\
\hline
\end{tabular}

Tyrosol and 2-PE are expressed as mg per $g$ of mycelial dry weight, and SA is expressed as $\mu \mathrm{g}$ per $g$ of mycelial dry weight. Values correspond to two independent biological replicates.
SPAD index and the leaf area of 4-week-old tomato plants between T6 or Tp-TC and Tparo7-silenced strain treatments (Table 8). The lowest size, dry weight and chlorophyll value were observed in tomato plants previously seed-coated with Tparo7silenced transformants. These data indicated that Tparo7 gene silencing negatively affects tomato plants. The results obtained in BC-infected tomato assays with strains T6, Tp-TC, Tparo7S3 and Tparo7-S4 showed that Tparo7 silencing also affected the biocontrol activity of $T$. parareesei (Table 8, Figure S4). The highest necrotic leaf area was observed in Tparo7-silenced transformant treatments and no statistically differences were observed among the necrotic lesion sizes observed for the T6 and Tp-TC treatments.

To test whether the tomato response to the different $T$. parareesei treatments involved the differential activation of systemic defense-related genes, we analyzed markers of the SA $(P R-1)$, JA (LOX1), and ET (EIN2) pathways using real-time

TABLE 7 | Colonization of tomato roots by T. parareesei wild-type (T6), control transformant (Tp-TC), and Tparo7-silenced transformants (Tparo7-S3 or Tparo7-S4)*.

\begin{tabular}{|c|c|c|c|c|c|c|c|}
\hline \multirow[t]{2}{*}{ Strain } & \multicolumn{3}{|c|}{ Tomato actin } & \multicolumn{3}{|c|}{ Trichoderma actin } & \multirow[t]{2}{*}{ Ratio ${ }^{\star \star \star \star}$} \\
\hline & Ct & SD & Qty $^{\star \star}$ & Ct & SD & Qty ${ }^{\star \star \star}$ & \\
\hline T6 & 20.82 & 0.06 & 144.52 & 16.87 & 0.02 & 24.58 & $0.17 \pm 0.01^{a}$ \\
\hline Tp-TC & 20.97 & 0.02 & 127.65 & 17.01 & 0.18 & 22.07 & $0.17 \pm 0.03^{a}$ \\
\hline Tparo7-S3 & 21.04 & 0.10 & 121.25 & 18.43 & 0.31 & 7.74 & $0.06 \pm 0.02^{b}$ \\
\hline Tparo7-S4 & 21.78 & 0.09 & 67.43 & 18.93 & 0.03 & 5.38 & $0.08 \pm 0.01^{b}$ \\
\hline
\end{tabular}

${ }^{\star}$ Fungal DNA present on the tomato roots $48 \mathrm{~h}$ after the inoculation was quantified by real-time PCR. Three replicates were made of each sample. Ct, threshold cycle and SD, standard deviation.

${ }^{* *}$ Quantity of tomato DNA (ng) referred to tomato actin gene.

${ }^{\star * \star}$ Quantity of Trichoderma DNA (ng) referred to Trichoderma actin gene.

${ }^{\star * * \star}$ Proportion of fungal DNA vs. plant DNA. Values are the means of the three replicates with the corresponding standard deviations and values followed by different superscript letters are significantly different $(P<0.05)$.

TABLE 8 | Effect of tomato seed treatment with T. parareesei T6, Tp-TC, Tparo7-S3 or Tparo7-S4 strains or not (control) on tomato plant growth (4-week-old plants) and necrotic leaf area caused by $B$. cinerea*.

\begin{tabular}{lccccc}
\hline Treatment & Control & T6 & Tp-TC & Tparo7-S3 & Tparo7-S4 \\
\hline Stem diameter (mm) & $5.31^{\mathrm{a}}$ & $5.24^{\mathrm{a}}$ & $5.21^{\mathrm{a}}$ & $3.81^{\mathrm{b}}$ & $4.12^{\mathrm{b}}$ \\
Stem height (cm) & $34.40^{\mathrm{a}}$ & $33.80^{\mathrm{a}}$ & $36.20^{\mathrm{a}}$ & $19.60^{\mathrm{b}}$ & $19.50^{\mathrm{b}}$ \\
Aboveground dry & $1.81^{\mathrm{a}}$ & $1.40^{\mathrm{a}}$ & $1.68^{\mathrm{a}}$ & $0.49^{\mathrm{b}}$ & $0.53^{\mathrm{b}}$ \\
weight (g) & & & & & \\
Root dry weight (g) & $0.28^{\mathrm{a}}$ & $0.27^{\mathrm{a}}$ & $0.29^{\mathrm{a}}$ & $0.15^{\mathrm{b}}$ & $0.16^{\mathrm{b}}$ \\
Chlorophyll (SPAD & $25.70^{\mathrm{a}}$ & $24.60^{\mathrm{a}}$ & $25.40^{\mathrm{a}}$ & $18.70^{\mathrm{b}}$ & $20.30^{\mathrm{b}}$ \\
index) & & & & & \\
Foliar area (cm $\left.{ }^{2}\right)$ & $8.42^{\mathrm{a}}$ & $7.09^{\mathrm{a}}$ & $7.53^{\mathrm{a}}$ & $4.01^{\mathrm{b}}$ & $5.53^{\mathrm{b}}$ \\
Necrotic foliar area (\%) & $1.61^{\mathrm{b}}$ & $1.59^{\mathrm{b}}$ & $1.52^{\mathrm{b}}$ & $21.68^{\mathrm{a}}$ & $16.85^{\mathrm{a}}$ \\
\hline
\end{tabular}

Ten plants were considered for each condition. Foliar area and necrotic foliar area were evaluated using ImageJ software.

*One leaf from each plant was inoculated on three leaflets using $10 \mu /$ containing $2500 \mathrm{~B}$. cinerea conidia/point and the necrotic leaf area was evaluated after 3 days. In each line, means followed by different superscript letters are significantly different $(P<0.05)$. 
PCR in tomato leaves from 4-week-old plants. Marker gene expression in tomato plants from in vivo assays is shown in Figure 5. In comparison with the control, T. parareesei seedcoated tomato plants showed significantly increased expression levels of $P R-1$, whereas no differences were detected among strains. This result shows that SA pathway was induced at 4 weeks after $T$. parareese $i$ treatment, which indicates a long-term systemic acquired resistance response elicited by $T$. parareesei. At the same time, EIN2 and LOX1 were downregulated in tomato seedlings from seeds treated with the Tparo7-silenced transformants and no statistically significant differences were observed among their expression levels in control plants and Tp-TC seed-coated plants.

\section{DISCUSSION}

Because the use of biofertilizers and biopesticides is an alternative for sustaining high production with low ecological impact, the development of research addressing biological control is currently expanding exponentially. Regarding the biocontrol of plant diseases, Trichoderma-based products are the most important biofungicides (Lorito et al., 2010), because selected Trichoderma strains have beneficial effects on plants, which can be explained in terms of plant growth promotion and the biological control of plant pathogens (Hermosa et al., 2012). Although T. parareesei T6 was able to achieve its best growth at $37^{\circ} \mathrm{C}$ and this temperature is closely related to the optimal growth temperature range of human pathogens, this species has not been neither isolated nor related to human disease and the continuous use of this strain in the laboratory has not resulted hazardous. In any case, risk assessment studies are needed before considering any in vivo application of this species in commercial agriculture (Rubio et al., 2014). The present study focuses on the role a $T$. parareesei $\mathrm{CM}$ in biocontrol and the induction of plant responses. This enzyme catalyzes the conversion of chorismate to prephenate, the precursor of the AAA Tyr and Phe, and constitutes a diverted node of the shikimate pathway, a biosynthetic network for primary and secondary metabolites. Contrary to what has been reported for $T$. reesei, with limited biocontrol activity, T. parareese $i$ is able to antagonize fungal and oomycete plant pathogens (Atanasova et al., 2010; Rubio et al., 2014). Since the genome of T. parareesei has not been annotated and no functional studies of the shikimate pathway have been reported in Trichoderma, we applied a genomic approach, taking advantage of the whole genome sequence of $T$. reesei (Martinez et al., 2008). At least eight genes encoding putative enzymes of the shikimate pathway from E-4P and PEP to prephenate were identified in T. reesei (Figure 1), and the one corresponding to a CM was used to design oligonucleotides to isolate the Tparo7 gene in T. parareesei. As expected, among the CMs previously characterized functionally TpARO7 showed the highest identity with the cytosolic CMs of filamentous ascomycetes (Krappmann et al., 1999). In addition, TpARO7 displayed more sequence identity with CMs from bacteria and plants than that observed
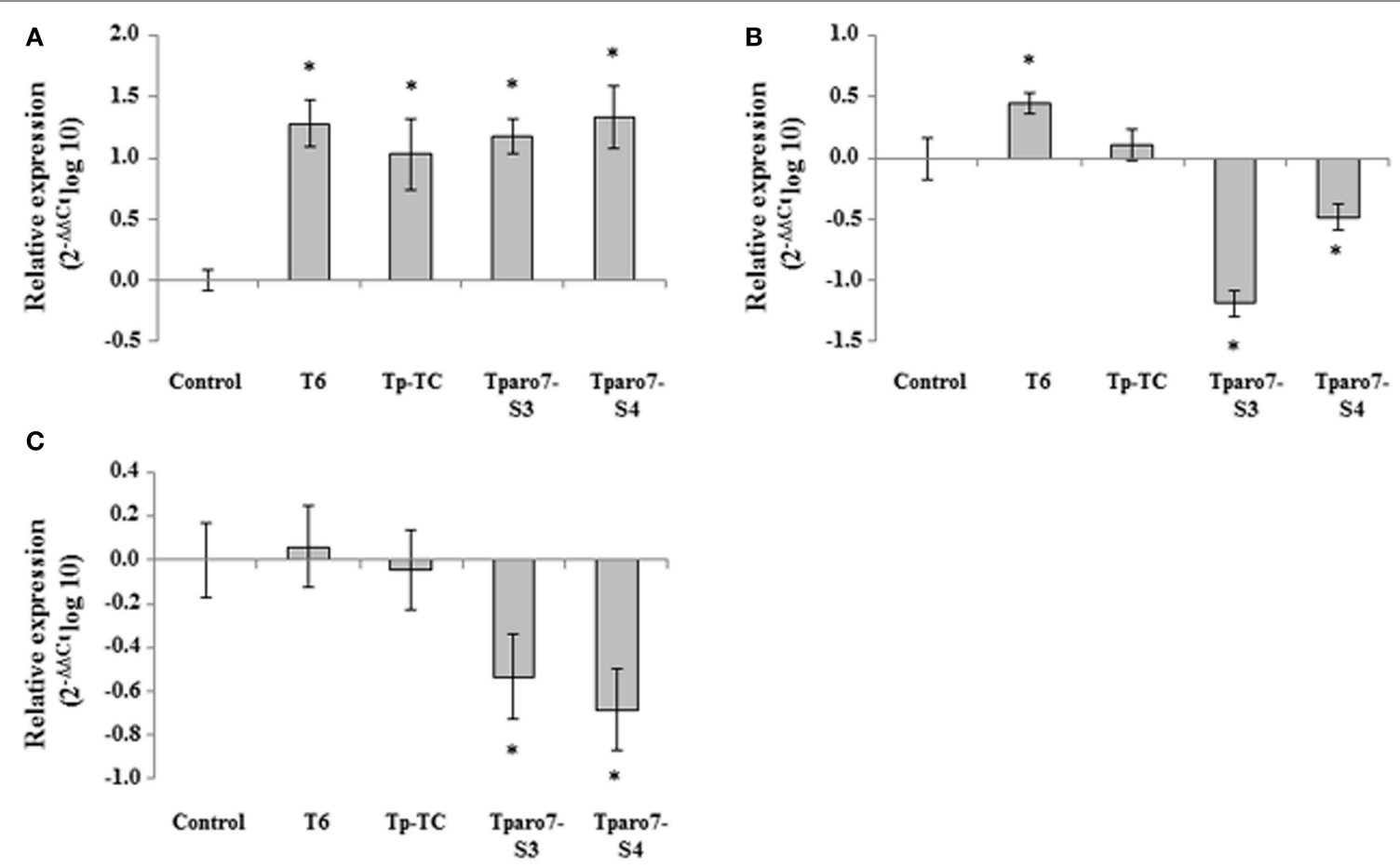

FIGURE 5 | Relative expression of the PR-1 (A), LOX1 (B), and EIN2 (C) genes in 4-week-old tomato leaves from seeds coated with a conidial suspension of T. parareesei T6, Tp-TC, Tparo7-S3, and Tparo7-S4. Values correspond to relative measurements against the transcripts in tomato leaves from untreated seeds $\left(2^{-\Delta \Delta C t}=1\right)$. Tomato actin was used as an internal reference gene. Bars represent the standard deviations of the mean of three replicates. Asterisk $\left(^{*}\right)$ represents statistically significant differences $(P<0.05)$. 
with the secreted Cmul of $U$. maydis (Djamei et al., 2011). The catalytic residues $\mathrm{R}^{20}, \mathrm{E}^{27}, \mathrm{R}^{162}, \mathrm{~K}^{173}, \mathrm{~T}^{250}$, and $\mathrm{E}^{254}$, which have been shown to be essential for the activity of some previously reported CMs, were also present in TpARO7.

CMs are normally feedback-inhibited by Tyr and/or Phe and induced by Trp, indicating allosteric regulation by AAA (Krappmann et al., 1999; Tzin and Galili, 2010). The in vitro CM activities calculated after the incubation of $T$. parareesei T6 protein extracts in the presence of AAA revealed feedback inhibition by Tyr and induction by Trp. Although Tparo7 transcript levels were significantly upregulated in strain T6 grown in MM supplemented with chorismic acid or AAA (Figure S1), the corresponding $\mathrm{CM}$ activities in intracellular protein from mycelia cultured in these media were lower than those calculated in MM (Table 1). These results are compatible with the aboveindicated regulation of CM by allosteric feedback-control of the different AAA. Since saprotrophic fungal growth has to adapt according to the surrounding environmental conditions, when AAA are scarce their biosynthesis should be regulated. Perhaps this occurred when T6 was incubated under imbalanced AAA sources, since many fungi possess the cross-pathway control system required to overcome an imbalanced amino acids diet, which is a complex process due to several feedback- or crossfeedback-controlled multi-amino acid pathways (Singh et al., 2010).

We generated CM mutant strains by RNA-mediated Tparo7 gene silencing. This strategy allows the functions of genes to be studied under conditions where they are essential, since small transcript levels are sufficient to keep the organism viable. This approach proved to be adequate to analyze genes functionally in T. harzianum (Cardoza et al., 2006). As in previous studies performed with Trichoderma silenced transformants (Cardoza et al., 2006; Morán-Diez et al., 2009), different degrees of silencing were observed among the Tparo7-silenced mutants at both the transcript and CM activity levels (Figure 2 and Table 2). We observed that Tparo7 expression and CM activity were related, and only a residual enzymatic activity was detected for the silenced transformant Tparo7-S4, which showed the lowest transcript levels. No correlation was observed between the number of pSIL-ARO7 copies inserted and the gene expression levels and CM activity. In fact, compared to the T6 and the TpTC strains, the highest Tparo7 expression observed in Tparo7-S2 grown in PDB (Figure S2) was accompanied by the highest CM activity. This same lack of correlation has also been reported for some other genes overexpressed or silenced in Trichoderma (Limón et al., 1999; Montero-Barrientos et al., 2007; MoránDiez et al., 2009). The differences in Tparo7 expression and CM activity between $\mathrm{T} 6$ and Tp-TC observed in some culture media are indicative of the fact that the insertion of the transformation cassette can affect this key regulation point of the primary metabolism under such culture conditions. For this reason, both strains were included in all tests carried out in the present study, displaying similar behavior in most of them.

As expected for a gene encoding a primary metabolism major node enzyme, Tparo7-silenced strains showed lower growth rates than those of T6 or Tp-TC on different culture media (Table 3). This phenotype was more evident in MM, mainly when this medium was supplemented with a mixture of AAA. This suggests an allosteric feedback-control of TpARO7 by AAA. Interestingly, Tparo7-S4, the strain with the lowest CM activity, showed the lowest growth rates at early incubation times (see Figure S3). However, this silenced mutant presented faster growth than Tparo7-S3 between 24 and $48 \mathrm{~h}$ of incubation (Table 3 ). This behavior, observed in several media, could be provoked by the complex regulation of the shikimate pathway just to stay alive despite of its high degree of CM silencing.

It is known that the biocontrol potential of Trichoderma varies depending upon the strains confronted (Atanasova et al., 2013). It could be proposed that the lower growth rate of Tparo-S3 and Tparo-S4 could be the cause of the reduced antagonistic ability displayed by these mutants against FO, RS and BC in dual cultures (Figure 3 and Figure S3). However, the limited mycoparasitic efficiency of the silenced mutants against FO and BC cannot be explained on the basis of fitness or substrate competition, but instead by other Trichoderma biocontrol mechanisms. Tparo7 silencing affected CW-degrading enzyme production in terms of reduced protease and increased chitinase activities. Recent studies based on transcriptomic analyses have indicated that proteolysis is a major biological process involved in the mycoparasitism of Trichoderma overgrowing its prey (Atanasova et al., 2013; Steindorff et al., 2014). The increased chitinase activity detected in Tparo7-silenced strains has also been reported when the tri4 gene, involved in trichothecene production, was disrupted or silenced in $T$. arundinaceum (Malmierca et al., 2012). It has been documented that exogenous supply of SA or culture media, which contain high levels of SA, induce chitinase activity in plant cells (Schneider-Müller et al., 1994), and that $\mathrm{Ca}^{2+}$ plays an important role in the production of chitinase and SA (Schneider-Müller et al., 1994; Kawano et al., 1998). Although $\mathrm{Ca}^{2+}$ concentrations were not calculated in the present study, we have observed a correlation between SA production and chitinase activity in the different $T$. parareesei strains. In particular, Tparo7-S3 showed the maximum SA levels accompanied by the highest chitinase activity. In any case, this correlation needs to be further explored in fungi. These results would justify the unexpected high BC inhibition activity detected in membrane assays for Tparo7-S3. In these assays, performed on medium where $T$. parareese $i$ was previously grown for $24 \mathrm{~h}$, the above indicated scarce growth of Tparo7S4 during the first hours of incubation could explain its low inhibition percentages recorded against the three pathogens (Table 4). However, membrane and supernatant assays have different experimental designs and results cannot be compared. In the tests performed with $48 \mathrm{~h}$-PDB supernatants, those from Tparo7-S3 showed the highest antifungal activity against FO and $\mathrm{BC}$, the two pathogens assayed (Figure 4). Moreover, taking into account that Tparo7-S4 has less growth than T6 and Tp-TC, its supernatant did not show reduced antifungal activity against these two pathogens at different incubation times. This is in agreement with the increased production of the AAA-derived antifungal compounds 2-PE, tyrosol and SA detected in both Tparo7-silenced mutants (Table 6). Thus, Tparo7 silencing has a positive effect on metabolite production in T. parareesei. An explanation for this is that $\mathrm{CM}$ activity could be compromised 
in Tparo7-silenced mutants and it has been reported that this enzyme is allosterically regulated by Tyr and Phe (Krappmann et al., 1999; Tzin and Galili, 2010). Thus, the conversion of Tyr and Phe into tyrosol and 2-PE respectively would prevent the allosteric inhibition of CM by these two amino acids. The production of tyrosol and 2-PE has been reported previously in Trichoderma spp. (Tarus et al., 2003), and a collateral tyrosol production has been identified in T. brevicompactum mutants overexpressing a trichodiene synthase involved in the biosynthesis of trichothecene compounds with antifungal activity (Tijerino et al., 2011). It has also been described previously that tyrosol, 2-PE and SA are part of the biocontrol strategies of yeast and bacteria against phytopathogens (Mercado-Blanco et al., 2001; Tarus et al., 2003; Liu et al., 2014). Bearing in mind the biocontrol assay data, the SM levels resulting from Tparo7 silencing would affect the production of CWdegrading enzymes and hence the mycoparasitic activity of T. parareesei.

Successful colonization is considered to be a major premise for the beneficial effects exerted by Trichoderma on plants (Harman et al., 2004; Morán-Diez et al., 2009; Hermosa et al., 2012). Our results concerning tomato root colonization by $T$. parareese $i$ strains are in agreement with the growth rates calculated in different media. However, if the lower root colonization capacity observed for Tparo7-silenced mutants as compared to those of the control strains (Table 7) were a direct consequence of their limited growth, there would be insufficient data to support the notion that TpARO7 plays a major role in the $T$. parareese $i$ rhizosphere colonization process. Since several reports have shown that Trichoderma SMs can affect plant growth and defense (Viterbo et al., 2007; Vinale et al., 2008; Tijerino et al., 2011; Malmierca et al., 2012, 2015), we used in vivo assays to explore the role of Tparo 7 in $T$. parareesei-tomato interactions. In comparison with control plants, we observed significantly lower growth parameters in plants whose seeds had been coated with Tparo7-silenced mutants (Table 8); this could be explained by their higher SA production (Table 6). We also observed that exogenous applications of $2-100 \mu \mathrm{M}$ tyrosol increased tomato seed germination but concentrations higher than $250 \mu \mathrm{M}$ elicited the opposite effect (data not shown). It has been reported that the effect of exogenous SA on growth depends on the plant species, the developmental stage and the SA concentrations tested, since low amounts of SA can have growth-stimulating effects but higher SA concentrations have been associated with reduced growth and chlorophyll content (Kovácik et al., 2009; Rivas-San Vicente and Plasencia, 2011). We analyzed the production of tyrosol, 2-PE and SA by T. parareesei strains, but differences in the biosynthesis of other metabolites could occur after Tparo7 silencing, since the shikimate pathway is strongly regulated and a huge variety of metabolites can be derived from it. We also observed that tomato plants treated with Tparo7-silenced mutants showed reduced protection against $\mathrm{BC}$, which would be in agreement with the observed downregulation of LOX1 and
EIN2 (Figure 5), involved in induced systemic resistance against necrotrophs.

As far as we know this is the first report relating CM silencing with biocontrol. The results concerning CM reported in this article support the hypothesis that SMs produced in the shikimate pathway are involved in the biocontrol potential of $T$. parareese $i$ and some of them appear to be key molecules for maintaining a proper balance in the responses elicited by $T$. parareesei during its interaction with plants. The observed relationships between AAA-derived SM production and CW degrading enzyme activity, already described in plants, need to be explained in fungi and the $T$. parareesei CM-silenced mutants obtained in the present work can be a touchstone to pursuing this goal.

\section{ACKNOWLEDGMENTS}

Research project funding was from the Spanish Ministry of Economy and Competitiveness (Projects no. AGL2012-40041C01 and AGL2012-40041-C02) and the Junta de Castilla y León (Projects no. LE125A12-2 and LE228U14). Esclaudys Pérez was endowed with a Spanish Foreign Office AECID award and Wagner Bettiol was supported by a fellowship from the Fundação de Amparo à Pesquisa do Estado de São Paulo_FAPESP (Project no. 2014/03426-1).

\section{SUPPLEMENTARY MATERIAL}

The Supplementary Material for this article can be found online at: http://journal.frontiersin.org/article/10.3389/fmicb. 2015.01181

\section{Figure S1 | Expression of Tparo7 gene in T. parareesei T6 by real-time PCR. Total RNA was extracted from mycelia grown for $48 \mathrm{~h}$ on PDB and transferred to MM containing 2\% glucose (MM) or $5 \mathrm{mM}$ Tyr (MM-Tyr), Phe (MM-Phe), Trp (MM-Trp) or chorismic acid (MM-chorismic acid) for $24 \mathrm{~h}$. Values correspond to relative measurements against the Tparo7 transcript in T6 grown in MM containing $2 \%$ glucose $\left(2^{-\Delta \Delta C t}=1\right)$. T. parareesei T6 actin was used as internal reference gene. Bars represent the standard deviations of the mean of three replicates. Asterisk (*) represents statistically significant differences $(P<0.05)$.}

Figure S2 | Southern blot analysis of wild type (T6) and transformant strains. Genomic DNAs were Sacl-digested and the phleomycin gene was used as probe. T. parareesei T6 (line 1), Tparo7-S1 (line 2), Tparo7-S2 (line 3), Tparo7-S3 (line 4), and Tparo7-S4 (line 5). HindllI-digested $\lambda$ DNA was used as a marker and molecular sizes are indicated in kbp (line M).

Figure S3 | Dual cultures of strains T6, the silenced transformants Tparo7-S3 and Tparo7-S4, and the control transformant Tp-TC of $T$. parareesei and the pathogen $\boldsymbol{B}$. cinerea $(\mathrm{BC})$ on PDA medium. Plates in the center correspond to the pathogen growth without Trichoderma strain. Plates were incubated at $28^{\circ} \mathrm{C}$ for 18 (A), 48 (B), and 72 (C) $\mathrm{h}$.

Figure S4 | Necrotic lesions observed in tomato leaves after T. parareesei seed treatment and B. cinerea conidia infection. Untreated seed and $B$. cinerea-infected leaves (control) and T. parareesei T6-, control transformant Tp-TC-, silenced transformants Tparo7-S3- and Tparo7-S4-treated seed and B. cinerea-infected leaves. Image was taken three days after $B$. cinerea-infection. 


\section{REFERENCES}

Atanasova, L., Le Crom, S., Gruber, S., Coulpier, F., Seidl-Seiboth, V., Kubicek, C. P., et al. (2013). Comparative transcriptomics reveals different strategies of Trichoderma mycoparasitism. BMC Genomics 14:121. doi: 10.1186/1471-216414-121

Atanasova, L., Jaklitsch, W. M., Komon-Zelazowska, M., Kubicek, C. P., and Druzhinina, I. S. (2010). Clonal species Trichoderma parareesei sp. nov. likely resembles the ancestor of the cellulose producer Hypocrea jecorina/T. reesei. Appl. Environ. Microbiol. 76, 7259 -7267. doi: 10.1128/AEM.01184-10

Bentley, R. (1990). The shikimate pathway-a metabolic tree with many branches. Crit. Rev. Biochem. Mol. Biol. 25, 307-384. doi: 10.3109/10409239009090615

Bradford, M. M. (1976). A rapid and sensitive method for the quantitation of microgram quantities of protein utilizing the principle of protein-dye binding. Anal. Biochem. 72, 248-254. doi: 10.1016/0003-2697(76) 90527-3

Brotman, Y., Landau, U., Cuadros-Inostroza, Á., Takayuki, T., Fernie, A. R., Chet, I., et al. (2013). Trichoderma-plant root colonization: escaping early plant defense responses and activation of the antioxidant machinery for saline stress tolerance. PLoS Pathog. 9:e1003221. doi: 10.1371/journal.ppat.1003221

Cardoza, R. E., Vizcaíno, J. A., Hermosa, M. R., Sousa, S., González, F. J., Llobell, A., et al. (2006). Cloning and characterization of the erg1 gene of Trichoderma harzianum: effect of the erg1 silencing on ergosterol biosynthesis and resistance to terbinafine. Fungal Genet. Biol. 43, 269-283. doi: 10.1016/j.fgb.2005.11.002

Davidson, B. E., and Hudson, G. S. (1987). Chorismate mutase-prephenate dehydrogenase from Escherichia coli. Methods Enzymol. 142, 440-450. doi: 10.1016/S0076-6879(87)42055-7

Degenkolb, T., Gräfenhan, T., Berg, A., Nirenberg, H. I., Gams, W., and Brückner, H. (2006). Peptaibiomics: screening for polypeptide antibiotics (peptaibiotics) from plant-protective Trichoderma species. Chem. Biodivers. 3, 593-610. doi: 10.1002/cbdv.200690063

Dellaporta, S. L., Wood, J., and Hicks, J. B. (1983). A plant DNA minipreparation: version II. Plant Mol. Biol. Rep. 1, 19-21. doi: 10.1007/BF02712670

Djamei, A., Schipper, K., Rabe, F., Ghosh, A., Vincon, V., Kahnt, J., et al. (2011). Metabolic priming by a secreted fungal effector. Nature 478, 395. doi: 10.1038/nature 10454

Druzhinina, I. S., Komon-Zelazowska, M., Atanasova, L., Seidl, V., and Kubicek, C. P. (2010). Evolution and ecophysiology of the industrial producer Hypocrea jecorina (anamorph Trichoderma reesei) and a new sympatric related to it. PLoS ONE 5:e9191. doi: 10.1371/journal.pone.0009191

Druzhinina, I. S., Seidl-Seiboth, V., Herrera-Estrella, A., Horwitz, B. A., Kenerley, C. M., Monte, E., et al. (2011). Trichoderma: the genomics of opportunistic success. Nat. Rev. Microbiol. 9, 749-759. doi: 10.1038/nrmicro2637

Fleet, G. H., and Phaff, H. J. (1974). Glucanases in Schizosaccharomyces. Isolation and properties of the cell wall-associated beta-(1,3)-glucanases. J. Biol. Chem. 249, 1717-1728.

Gu, W., Williams, D. S., Aldrich, H. C., Xie, G., Gabriel, D. W., and Jensen, R. A. (1997). The AroQ and PheA domains of the bifunctional P-protein from Xanthomonas campestris in a context of genomic comparison. Microb. Comp. Genomics 2, 141-158. doi: 10.1089/omi.1.1997.2.141

Gutiérrez, S., Velasco, J., Marcos, A. T., Fernández, F. J., Fierro, F., Barredo, J. L., et al. (1997). Expression of the cefG gene is limiting for cephalosporin biosynthesis in Acremonium chrysogenum. Appl. Microbiol. Biotechnol. 48, 606-614. doi: 10.1007/s002530051103

Harman, G. E., Howell, C. R., Viterbo, A., Chet, I., and Lorito, M. (2004). Trichoderma species opportunistic, avirulent plant symbionts. Nat. Rev. Microbiol. 2, 43-56. doi: 10.1038/nrmicro797

Harman, G. E., Obregon, M. A., Samuels, G. J., and Lorito, M. (2010). Changing models for commercialization and implementation of biocontrol in the developed and developing world. Plant Dis. 94, 928-939. doi: 10.1094/PDIS94-8-0928

Helmstaedt, K., Krappmann, S., and Braus, G. H. (2001). Allosteric regulation of catalytic activity: Escherichia coli aspartate transcarbamoylase versus yeast chorismate mutase. Microbiol. Mol. Biol. Rev. 65, 404-421. doi: 10.1128/MMBR.65.3.404-421.2001

Hermosa, R., Viterbo, A., Chet, I., and Monte, E. (2012). Plant-beneficial effects of Trichoderma and of its genes. Microbiology 158, 17-25. doi: $10.1099 /$ mic.0.052274-0
Holwerda, B. C., and Rogers, J. C. (1992). Purification and characterization of aleurain: a plant thiol protease functionally homologous to mammalian cathepsin H. Plant Physiol. 99, 848-855. doi: 10.1104/pp.99. 3.848

Kawano, T., Sahashi, N., Takahashi, K., Uozumi, N., and Muto, S. (1998). Salicylic acid induces extracellular superoxide generation followed by an increase in cytosolic calcium ion in tobacco suspension culture: the earliest events in salicylic acid signal transduction. Plant Cell Physiol. 39, 721-730. doi: 10.1093/oxfordjournals.pcp.a029426

Kovácik, J., Grúz, J., Backor, M., Strnad, M., and Repcák, M. (2009). Salicylic acidinduced changes to growth and phenolic metabolism in Matricaria chamomilla plants. Plant Cell Rep. 28, 135-143. doi: 10.1007/s00299-008-0627-5

Krappmann, S., Helmstaedt, K., Gerstberger, T., Eckert, S., Hoffmann, B., Hoppert, M., et al. (1999). The aroC gene of Aspergillus nidulans codes for a monofunctional allosterically regulated chorismate mutase. J. Biol. Chem. 32, 22275-22282. doi: 10.1074/jbc.274.32.22275

Leeman, M., den Ouden, F. M., van Pelt, J. A., Steijl, H., Dirkx, F. P. M., Bakker, P. A. H. M., et al. (1996). Iron availability affects induction of systemic resistance to Fusarium wilt of radish by Pseudomonas fluorescens. Phytopathology 86, 149-155. doi: 10.1094/Phyto-86-149

Light, S. H., and Anderson, W. F. (2013). The diversity of allosteric controls at the gateway to aromatic amino acid biosynthesis. Protein Sci. 22, 395-404. doi: 10.1002 /pro. 2233

Limón, M. C., Pintor-Toro, J. A., and Benítez, T. (1999). Increased antifungal activity of Trichoderma harzianum transformants that overexpress a 33 kDa chitinase. Phytopathology 89, 254-261. doi: 10.1094/PHYTO.1999.89. 3.254

Liu, P., Cheng, Y., Yang, M., Liu, Y., Chen, K., Long, C., et al. (2014). Mechanisms of action for 2-phenylethanol isolated from Kloeckera apiculata in control of Penicillium molds of citrus fruits. BMC Microbiol. 14:242. doi: 10.1186/s12866014-0242-2

Livak, K. J., and Schmittgen, T. D. (2001). Analysis of relative gene expression data using real-time quantitative PCR and the 2(-delta delta CT) method. Methods 25, 402-408. doi: 10.1006/meth.2001.1262

Lorito, M., Woo, S. L., Harman, G. E., and Monte, E. (2010). Translational research on Trichoderma: from 'omics to the field. Ann. Rev. Phytopathol. 48, 395-417. doi: 10.1146/annurev-phyto-073009-114314

Malmierca, M. G., Barua, J., McCormick, S. P., Izquierdo-Bueno, I., Cardoza, R. E., Alexander, N. J., et al. (2015). Novel aspinolide production by Trichoderma arundinaceum with a potential role in Botrytis cinerea antagonistic activity and plant defence priming. Environ. Microbiol. 17, 1103-1118. doi: 10.1111/14622920.12514

Malmierca, M. G., Cardoza, R. E., Alexander, N. J., McCormick, S. P., Hermosa, R., Monte, E., et al. (2012). Involvement of Trichoderma trichothecenes in the biocontrol activity and induction of plant defense-related genes. Appl. Environ. Microbiol. 78, 4856-4868. doi: 10.1128/AEM.00385-12

Martinez, D., Berka, R. M., Henrissat, B., Saloheimo, M., Arvas, M., Baker, S. E., et al. (2008). Genome sequencing and analysis of the biomass-degrading fungus Trichoderma reesei (syn. Hypocrea jecorina). Nat. Biotechnol. 26, 553-560. doi: $10.1038 /$ nbt1403

Mercado-Blanco, J., van der Drift, K. M. G. M., Olsson, P. E., Thomas-Oates, J. E., van Loon, L. C., and Bakker, P. A. H. M. (2001). Analysis of the pmsCEAB gene cluster involved in biosynthesis of salicylic acid and the siderophore pseudomonine in the biocontrol strain Pseudomonas fluorescens WCS374. J. Bacteriol. 183, 1909-1920. doi: 10.1128/JB.183.6.1909-1920.2001

Montero-Barrientos, M., Cardoza, R. E., Gutiérrez, S., Monte, E., and Hermosa, R. (2007). The heterologous overexpression of hsp23 a small heat-shock gene from Trichoderma virens, confers thermotolerance to T. harzianum. Curr. Genet. 52, 45-53. doi: 10.1007/s00294-007-0140-3

Montero-Barrientos, M., Hermosa, R., Cardoza, R. E., Gutiérrez, S., and Monte, E. (2011). Functional analysis of the Trichoderma harzianum noxl gene, encoding an NADPH oxidase, relates production of reactive oxygen species to specific biocontrol activity against Pythium ultimum. Appl. Environ. Microbiol. 77, 3009-3016. doi: 10.1128/AEM.02486-10

Morán-Diez, E., Hermosa, R., Ambrosino, P., Cardoza, R. E., Gutiérrez, S., Lorito, M., et al. (2009). The ThPG1 endopolygalaturonase is required for the Trichoderma harzianum-plant beneficial interaction. Mol. Plant Microbe Int. 22, 1021-1031. doi: 10.1094/MPMI-22-8-1021 
Mukherjee, P. K., Horwitz, B. A., Herrera-Estrella, A., Schmoll, M., and Kenerley, C. M. (2013). Trichoderma research in the genomic era. Annu. Rev. Phytopathol. 51, 105-129. doi: 10.1146/annurev-phyto-082712-102353

Murashige, T., and Skoog, F. (1962). A revised medium for rapid growth and bioassays with tobacco tissue cultures. Physiol. Plantarum 15, 473-497. doi: 10.1111/j.1399-3054.1962.tb08052.x

Penttilä, M., Nevalainen, H., Rättö, M., Salminen, E., and Knowles, J. (1987). A versatile transformation system for the cellulolytic filamentous fungus Trichoderma reesei. Gene 61, 155-164. doi: 10.1016/0378-1119(87)90110-7

Raeder, U., and Broda, P. (1985). Rapid preparation of DNA from filamentous fungi. Lett. Appl. Microbiol. 1, 17-20. doi: 10.1111/j.1472-765X.1985.tb01479.x

Reino, J. L., Guerrero, R. F., Hernández-Galán, R., and Collado, I. G. (2008). Secondary metabolites from species of the biocontrol agent Trichoderma. Phytochem. Rev. 7, 89-123. doi: 10.1007/s11101-006-9032-2

Reissig, J. L., Strominger, J. L., and Leloir, L. F. (1955). A modified colorimetric method for the estimation of N-acetylamino sugars. J. Biol. Chem. 217, 959-966.

Rivas-San Vicente, M., and Plasencia, J. (2011). Salicylic acid beyond defence: its role in plant growth and development. J. Exp. Bot. 62, 3321-3338. doi: $10.1093 / \mathrm{jxb} / \mathrm{err} 031$

Romero, R. M., Roberts, M. F., and Phillipson, J. D. (1995). Chorismate mutase in microorganisms and plants. Phytochemistry 40, 1015-1025. doi: 10.1016/00319422(95)00408-Y

Rubio, M. B., Hermosa, R., Reino, J. L., Collado, I. G., and Monte, E. (2009). Thctf1 transcription factor of Trichoderma harzianum is involved in 6-pentyl- $2 \mathrm{H}$ pyran-2-one production and antifungal activity. Fungal Genet. Biol. 46, 17-27. doi: 10.1016/j.fgb.2008.10.008

Rubio, M. B., Quijada, N. M., Pérez, E., Domínguez, S., Monte, E., and Hermosa, R. (2014). Identifying beneficial qualities of Trichoderma parareesei for plants. Appl. Environ. Microbiol. 80, 1864-1873. doi: 10.1128/AEM. 03375-13

Sasso, S., Ramakrishnan, C., Gamper, M., Hilvert, D., and Kast, P. (2004). Characterization of the secreted chorismate mutase from the pathogen Mycobacterium tuberculosis. FEBS J. 272, 375-389. doi: 10.1111/j.17424658.2004.04478.x

Schirmböck, M., Lorito, M., Wang, Y. L., Hayes, C. K., Arisan-Atac, I., Scala, F., et al. (1994). Parallel formation and synergism of hydrolytic enzymes and peptaibol antibiotics, molecular mechanisms involved in the antagonistic action of Trichoderma harzianum against phytopathogenic fungi. Appl. Environ. Microbiol. 60, 4364-4370.

Schneider-Müller, S., Kurosaki, F., and Nishi, A. (1994). Role of salicylic acid and intracellular $\mathrm{Ca}^{2+}$ in the induction of chitinase activity in carrot suspension culture. Physiol. Mol. Plant Pathol. 45, 101-109. doi: 10.1016/S08855765(05)80069-4

Singh, S., Brauss-Stromeyer, S. A., Timpner, C., Tran, T. T., Lohaus, G., Reusche, M., et al. (2010). Silencing of Vlaro2 for chorismate synthase revealed that the phytopathogen Verticillium longisporum induces the cross-pathway control in the xylem. Appl. Microbiol. Biotechnol. 85, 1961-1976. doi: 10.1007/s00253-0092269-0
Steindorff, A. S., Ramada, M. H. S., Coelho, A. S. G., Miller, R. N. G., Pappas, G. J. Jr., Uhloa, C. J., et al. (2014). Identification of mycoparasitism-related genes against the phytopathogen Sclerotinia sclerotiorum through transcriptome and expression profile analysis in Trichoderma harzianum. BMC Genomics 15:204. doi: 10.1186/1471-2164-15-204

Sträter, N., Schnappauf, G., Braus, G., and Lipscomb, W. N. (1997). Mechanisms of catalysis and allosteric regulation of yeast chorismate mutase from crystal structures. Structure 5, 1437-1452. doi: 10.1016/S0969-2126(97)00294-3

Tarus, P. K., Lang'at-Thoruwa, C. C., Wanyonyi, A. W., and Chhabra, S. C. (2003). Bioactive metabolites from Trichoderma harzianum and Trichoderma longibrachiatum. Bull. Chem. Soc. Ethiopia 17, 185-190. doi: 10.4314/bcse.v17i2.61675

Thompson, J. D., Higgins, D. G., and Gibson, T. J. (1994). CLUSTAL W: improving the sensitivity of progressive multiple sequence alignment through sequence weighting, position-specific gap penalties and weight matrix choice. Nucleic Acids Res. 22, 4673-4680. doi: 10.1093/nar/22.22.4673

Tijerino, A., Cardoza, R. E., Moraga, J., Malmierca, M. G., Vicente, F., Aleu, J., et al. (2011). Overexpression of the trichodiene synthase gene tri5 increases trichodermin production and antimicrobial activity in Trichoderma brevicompactum. Fungal Genet. Biol. 48, 285-296. doi: 10.1016/j.fgb.2010.11.012

Tohge, T., Watanabe, M., Hoefgen, R., and Fernie, A. R. (2013). Shikimate and phenylalanine biosynthesis in the green lineage. Front. Plant Sci. 4:62. doi: $10.3389 /$ fpls.2013.00062

Tzin, V., and Galili, G. (2010). New insights into the shikimate and aromatic amino acids biosynthesis pathways in plants. Mol. Plant 3, 956-972. doi: $10.1093 / \mathrm{mp} / \mathrm{ssq} 048$

Vinale, F., Sivasithamparam, K., Ghisalberti, E. L., Marra, R., Barbetti, M. J., Li, H., et al. (2008). A novel role for Trichoderma secondary metabolites in the interactions with plants. Physiol. Mol. Plant Pathol. 72, 80-86. doi: 10.1016/j.pmpp.2008.05.005

Viterbo, A., Wiest, A., Brotman, Y., Chet, I., and Kenerley, C. (2007). The 18mer peptaibols from Trichoderma virens elicit plant defence responses. Mol. Plant Pathol. 8, 737-746. doi: 10.1111/j.1364-3703.2007.00430.x

Vogt, T. (2010). Phenylpropanoid biosynthesis. Mol. Plant 3, 2-20. doi: $10.1093 / \mathrm{mp} / \mathrm{ssp} 106$

Conflict of Interest Statement: The authors declare that the research was conducted in the absence of any commercial or financial relationships that could be construed as a potential conflict of interest.

Copyright (๑ 2015 Pérez, Rubio, Cardoza, Gutiérrez, Bettiol, Monte and Hermosa. This is an open-access article distributed under the terms of the Creative Commons Attribution License (CC BY). The use, distribution or reproduction in other forums is permitted, provided the original author(s) or licensor are credited and that the original publication in this journal is cited, in accordance with accepted academic practice. No use, distribution or reproduction is permitted which does not comply with these terms. 